\title{
PREVALENSI NYERI NEUROPATIK PADA PASIEN DENGAN NYERI KANKER DI RSUPN DR CIPTO MANGUNKUSUMO DAN PKN RS DHARMAIS
}

\author{
NEUROPATHIC PAIN PREVALENCE AMONG CANCER PAIN PATIENTS IN \\ CIPTO MANGUNKUSUMO AND DHARMAIS HOSPITAL
}

\author{
Henry Riyanto Sofyan, * Tiara Aninditha, ${ }^{*}$ Louis Kwandou, **Jonathan Odilo, *** Rini Andriani****
}

\section{ABSTRACT}

Introduction: Cancer pain is one of the most common complications in cancer. As much as 30-50\% of cancer patients experienced pain. Cancer pain patients have reported complaints of pain with a neuropathic component. Early diagnosis of neuropathic cancer pain has a clinical implication for patient management. However, the proportion of neuropathic cancer pain has not been studied in Indonesian population.

Aim: The study was to get an overview of neuropathic pain prevalence among cancer pain patients in Cipto Mangunkusumo General Hospital and National Cancer Referral Dharmais Hospital.

Methods: The design of this research was cross-sectional. The study was done in Cipto Mangunkusumo General Hospital and National Cancer Referral Dharmais Hospital in July-September 2019. The subjects in this research were adult cancer patients who consulted with the Department of Neurology. The data acquired were patient's demography, cancer history, imaging, and pain assessment. PainDETECT questionnaire was employed to assess neuropathic pain. The data were processed and presented descriptively and analytically.

Results: There were 57 subjects obtained in this research with average age of 45.91 . As much as $31.6 \%$ subjects had neuropathic cancer pain. Breast cancer identified in $38.6 \%$ subjects. There were no differences of gender, age, cancer type, and pain intensity between subjects with and without neuropathic cancer pain. Radiating pain and subject with metastasis experienced neuropathic cancer pain more frequently.

Discussion: The prevalence of neuropathic cancer pain in the Indonesian population is $31.6 \%$. Radiating pain and patients with metastasis cancer tend to experienced neuropathic pain more frequently.

Keywords: Cancer, Indonesia, neuropathic pain, prevalence

\section{ABSTRAK}

Pendahuluan: Nyeri kanker merupakan salah satu komplikasi paling sering pada kanker (30-50\%). Komponen nyeri neuropatik dapat ditemukan pada pasien. Diagnosis dini nyeri kanker neuropatik memiliki implikasi pada terapi. Namun, proporsi nyeri kanker neuropatik belum pernah diteliti di Indonesia.

Tujuan: Mendapatkan prevalensi dan karakteristik nyeri neuropatik pada pasien nyeri kanker di RSUPN Dr. Cipto Mangunkusumo dan PKN RS Dharmais.

Metode: Penelitian ini dilakukan dengan disain potong lintang terhadap pasien nyeri kanker dewasa yang dikonsultasikan ke bagian Neurologi RSUPN Dr. Cipto Mangunkusumo dan Pusat Kanker Nasional RS Dharmais pada Juli-September 2019. Data yang diambil adalah demografi, riwayat kanker, pencitraan, dan pengkajian nyeri. Deteksi nyeri neuropatik dikaji menggunakan kuesioner PainDETECT yang sudah divalidasi ke dalam Bahasa Indonesia. Data disajikan secara deskriptif dan analitik.

Hasil: Didapatkan 57 subjek dengan rerata usia 45,91. Sebanyak 31,6\% pasien mengalami nyeri kanker neuropatik. Kanker payudara didapati pada 38,6\% subjek. Tidak terdapat perbedaan bermakna antara jenis kelamin, umur, jenis kanker, dan intensitas nyeri antara subjek dengan dan tanpa nyeri kanker neuropatik. Nyeri menjalar dan subjek dengan metastasis mengalami nyeri neuropatik lebih sering.

Diskusi: Prevalensi nyeri kanker neuropatik pada populasi Indonesia sebesar 31,6\%. Nyeri menjalar dan pasien dengan kanker metastasis cenderung mengalami nyeri neuropatik lebih sering.

Kata kunci: Indonesia, nyeri kanker, nyeri neuropatik, prevalensi

*Departemen Neurologi FK Universitas Indonesia/RSUPN Dr. Cipto Mangunkusumo, Jakarta; **Fellow Neuroonkologi FK Universitas Indonesia, Jakarta/Departemen Neurologi FK Universitas Hasanuddin, Makassar; ***FK Universitas Indonesia, Jakarta; ****SMF Neurologi Pusat Kanker Nasional RS Dharmais, Jakarta. Korespondensi: henry.riyanto.sofyan@gmail.com.

\section{PENDAHULUAN}

Nyeri kanker adalah salah satu komplikasi yang sering ditemukan pada pasien dengan kanker, yaitu 30-50\% dan meningkat hingga 70\%-90\% pada kanker tahap lanjut. Seiring dengan perjalanan penyakit yang semakin memberat, nyeri ini dapat 
menyebabkan gangguan kejiwaan dan penurunan kualitas hidup pasien. ${ }^{1}$ Nyeri kanker merupakan nyeri dengan patofisiologi yang kompleks, sehingga hampir seluruh subtipe nyeri dapat dirasakan oleh penderitanya. ${ }^{1}$

Keluhan nyeri ini dapat dirasakan dalam setiap fase perkembangan kanker, mulai dari fase penegakan diagnosis ataupun telaah stadium kanker (staging), fase pembedahan, fase terapi, fase remisi, fase relaps, ataupun fase kesintasan (survivorship). Seiring perjalanan penyakit, nyeri kanker akan semakin intens. Hal ini disebabkan oleh kerusakan nosiseptor akibat pertumbuhan tumor. Selain itu, nosiseptor juga menjadi tersensitisasi oleh pelepasan faktor-faktor dari sel kanker dan sel stromal, misalnya nerve growth factor. Bila perjalanan penyakit kanker terus berlanjut, maka terjadi proses pembentukan regenerasi kecambah saraf (nerve sprouting) ektopik dan neuroma yang menimbulkan nyeri sontak (breakthrough pain). ${ }^{1}$

Sel tumor dan sel stromal dapat menginfiltrasi jaringan ikat di sekitarnya yang mengandung serabut saraf bebas. Sel abnormal ini akan menghancurkan bagian distal dari serabut saraf sensoris bebas, serta menyebabkan diskontinuitas dan fragmentasi sel saraf. Selain itu, sel saraf ini juga dapat mengalami kerusakan akibat kemoterapi, pembedahan, atau radiasi. Pada metastasis ke tulang vertebra dapat terjadi fraktur kompresi yang mengakibatkan kerusakan pedikel dan menekan radiks, sehingga menimbulkan nyeri radikular. Kesemua hal itu menyebabkan adanya komponen nyeri neuropatik pada nyeri kanker. ${ }^{1}$

Oleh karena itu, nyeri neuropatik pada kanker dapat disebabkan oleh berbagai hal seperti infiltrasi tumor, metastasis tumor, efek samping prosedur diagnostik atau terapeutik, reaktivasi infeksi, atau sindrom paraneoplastik, ${ }^{2}$ sehingga penderita kanker rentan mengalami nyeri ini. Dalam kesintasan yang dilakukan Roberto dkk pada tahun 2016, ditemukan bahwa terdapat $31,2 \%$ pasien dengan nyeri kanker mengalami nyeri neuropatik. ${ }^{3}$ Namun sayangnya nyeri ini kurang diperiksa secara khusus, padahal nyeri kanker neuropatik tidak efektif diobati dengan opioid saja yang merupakan obat utama pada nyeri kanker.
Diperlukan ko-analgesik lain, seperti antikonvulsan dan antidepresan dalam penanganannya. Sementara keterlambatan dalam mendiagnosis dan pemberian obat dapat menurunkan kualitas hidup dari pasien, karena nyeri kanker neuropatik cenderung memiliki intensitas lebih tinggi dan durasi lebih lama dibandingkan nyeri jenis lain. ${ }^{4}$

Oleh karena itu, perlu dilakukan penapisan nyeri kanker neuropatik sedini mungkin saat pasien merasa nyeri. Salah satu alat skrining yang bisa digunakan untuk mendeteksi adanya komponen nyeri neuropatik adalah kuesioner PainDETECT. Kuesioner ini mulanya digunakan pada kasus nyeri punggung bawah (low back pain), namun sudah digunakan luas pada kasus lainnya dan sudah divalidasi ke dalam Bahasa Indonesia. ${ }^{5}$

Penelitian Tzamakou dkk menggunakan kuesioner PainDETECT pada pasien kanker mendapatkan sensitivitas dan spesifisitas 26,3\% dan $100 \%$ pada nilai potong $\geq 19$. Dengan nilai spesifisitas yang besar, kuesioner PainDETECT dapat menentukan pasien dengan nyeri kanker neuropatik. ${ }^{6}$ Namun sejauh ini belum ada data khusus prevalensi komponen nyeri neuropatik dan menggunakan kuesioner tersebut, serta dengan meningkatnya jumlah penderita kanker di Indonesia, maka perlu dilakukan penelitian ini.

\section{TUJUAN}

Studi dilakukan untuk mengetahui prevalensi dan karakteristik nyeri neuropatik pada pasien nyeri kanker di RSUPN Dr. Cipto Mangunkusumo dan Pusat Kanker Nasional (PKN) RS Dharmais.

\section{METODE}

Penelitian ini merupakan penelitian potong lintang yang dilakukan di Departemen Neurologi RSUPN Dr. Cipto Mangunkusumo dan PKN RS Dharmais dari Juli-September 2019. Kriteria inklusi adalah subjek yang mengalami nyeri kanker, kooperatif, dan dapat berkomunikasi secara verbal. Adapun kriteria eksklusi adalah nyeri kepala akibat tumor intrakranial atau memiliki gangguan kognitif.

Nyeri kanker ditegakkan berdasarkan adanya nyeri pada area anatomis yang berhubungan dengan massa berdasarkan gejala klinis dan gambaran imaging 
Tabel 1. Karakteristik Demografi Subjek Penelitian $(\mathbf{n}=\mathbf{5 7})$

\begin{tabular}{|c|c|}
\hline Variabel & n $(\%)$ \\
\hline Usia (tahun), Rerata \pm SD & $45,91 \pm 12,41$ \\
\hline $\begin{array}{ll}\text { Jenis } & \text { Kelamin } \\
\text { - } & \text { Laki-Laki } \\
\text { - } & \text { Perempuan }\end{array}$ & $\begin{array}{l}20(35,1) \\
37(64,9)\end{array}$ \\
\hline 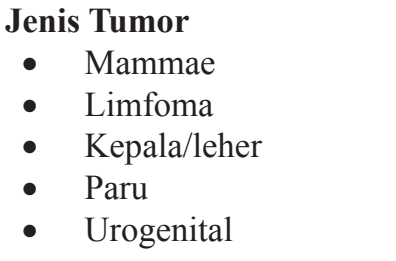 & $\begin{array}{c}22(38,6) \\
7(12,3) \\
11(19,3) \\
5(8,8) \\
12(21,1)\end{array}$ \\
\hline $\begin{array}{l}\text { Nyeri Neuropatik } \\
\text { - Ya } \\
\text { - } \quad \text { Tidak }\end{array}$ & $\begin{array}{l}18(31,6) \\
39(68,4)\end{array}$ \\
\hline 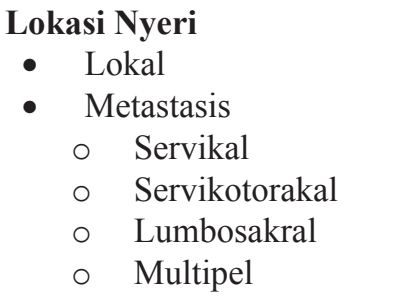 & $\begin{array}{c}12(21,1) \\
45(78,9) \\
14(24,6) \\
9(15,3) \\
19(33,3) \\
3(5,3)\end{array}$ \\
\hline $\begin{array}{ll}\text { Terapi Nyeri } \\
\text { - } \\
\text { - } \\
\text { - } & \text { Kemodioterapi } \\
\text { - } & \text { Opioid } \\
\text { - } & \text { Anabapentin } \\
& \text { Analgetik non-opioid }\end{array}$ & $\begin{array}{c}8(14) \\
6(10,5) \\
46(80,7) \\
21(36,8) \\
8(14)\end{array}$ \\
\hline $\begin{array}{l}\text { Respons terhadap Terapi } \\
\text { - Ya } \\
\text { - } \quad \text { Tidak }\end{array}$ & $\begin{array}{l}37(64,9) \\
20(35,1)\end{array}$ \\
\hline
\end{tabular}

SD: standar deviasi

yang sesuai. ${ }^{1,7}$ Adanya komponen nyeri neuropatik dinilai menggunakan kuesioner Pain DETECT versi Bahasa Indonesia, yaitu jika nilai skor PainDETECT $\geq 19$. ${ }^{5-6}$

Variabel demografis dan klinis yang dianalisis pada penelitian adalah jenis kelamin, usia, terapi pada nyeri, lokasi nyeri, pola nyeri, karakteristik semantik pada nyeri, penjalaran nyeri, respons pada pengobatan nyeri, dan komponen nyeri neuropatik pada nyeri kanker. Intensitas nyeri dinilai menggunakan numerical rating scale (NRS), yaitu keadaan nyeri saat dilakukan pemeriksaan, intensitas terkuat dan rerata nyeri pada sebulan terakhir.

Pengolahan data dilakukan secara deskriptif dan analitik menggunakan SPSS ver. 25 for Windows. Normalitas data numerik akan diukur dengan tes Kolmogorov-Smirnov. Analisis bivariat komparatif menggunakan $t$-test tidak berpasangan jika sebaran data normal dan Mann-Whitney jika sebaran tidak normal. Uji Chi-square dilakukan pada data kategorik jika nilai expected seluruh sel $>5$. Jika uji Chi-square tidak memenuhi syarat, akan dilakukan uji Fisher. Data disajikan secara deskriptif dan analitik.

\section{HASIL}

Dalam penelitian ini, didapatkan terdapat 57 subjek penelitian dengan rerata usia $45,91 \pm 12,41$ tahun dan mayoritas perempuan $(64,9 \%)$. Jenis kanker terbanyak adalah kanker payudara $(38,6 \%)$, nyeri terutama di area metastasis spinal $(78,9 \%)$, dan nyeri neuropatik ditemukan pada 31,6\% subjek (Tabel 1). Sebanyak $80,7 \%$ subjek mendapat terapi opioid dan $36,8 \%$ berupa golongan antikonvulsan, hingga didapatkan penurunan nilai NRS $>50 \%$ pada $65 \%$ pasien.

Sebagian besar subjek mengalami nyeri dengan intensitas berat (NRS 8) baik pada kelompok nyeri neuropatik dan nyeri non-neuropatik, yaitu $66,7 \%$ vs $64,1 \%$. Subjek dengan nyeri neuropatik juga memiliki karakteristik nyeri yang menjalar $(\mathrm{p}=0,003)$, rasa terbakar $(\mathrm{p}=<0,001)$, alodinia $(\mathrm{p}=0,010)$, sensitivitas terhadap suhu $(\mathrm{p}=<0,001)$, kesemutan $(\mathrm{p}=<0,001)$, nyeri tekan $(p=0,008)$, baal $(p<0,001)$, dan sensasi tersetrum $(\mathrm{p}=<0,001)$ dibandingkan subjek dengan nyeri non-neuropatik (Tabel 2). Tidak terdapat perbedaan pola nyeri antara subjek dengan dan tanpa nyeri neuropatik, bahwa kedua kelompok mengalami nyeri yang hilang timbul tanpa rasa nyeri di antaranya.

Tabel 3 tidak mendapatkan perbedaan karakteristik subjek dengan nyeri neuropatik dengan nyeri non-neuropatik pada usia, jenis kelamin, dan jenis tumor. Namun seluruh pasien dengan nyeri neuropatik memiliki lokasi nyeri pada area metastasis tumornya dibandingkan dengan nyeri non-neuropatik $(\mathrm{p}=0,011)$.

\section{PEMBAHASAN}

Dalam penelitian ini ditemukan sebagian besar subjek $(64,9 \%)$ adalah perempuan, mirip dengan Couceiro dkk bahwa mayoritas pasien yang mengalami nyeri kanker adalah perempuan $(75,6 \%){ }^{8}$ Hal ini dimungkinkan karena jenis kanker terbanyak dalam penelitian ini kanker payudara $(38,6 \%)$ yang 
Tabel 2. Perbandingan Karakteristik pada Nyeri Neuropatik dan Nyeri Non-neuropatik $(n=57)$

\begin{tabular}{|c|c|c|c|}
\hline \multirow[b]{2}{*}{ Variabel } & \multicolumn{2}{|c|}{ Nyeri Neuropatik } & \multirow[b]{2}{*}{$\mathbf{p}$} \\
\hline & $\begin{array}{c}\text { Ya } \\
(n=18) \\
n(\%)\end{array}$ & $\begin{array}{c}\text { Tidak } \\
(\mathrm{n}=39) \\
\mathrm{n}(\%)\end{array}$ & \\
\hline $\begin{array}{l}\text { Intensitas Nyeri } \\
\text { - Sedang } \\
\text { - Berat }\end{array}$ & $\begin{array}{c}6(33,3) \\
12(66,7)\end{array}$ & $\begin{array}{l}14(35,9) \\
25(64,1)\end{array}$ & $0,850 *$ \\
\hline Rerata Nyeri Dalam 1 Bulan, Median (Min-maks) & $8(3-10)$ & $8(4-10)$ & $0,993^{\mathrm{a}}$ \\
\hline $\begin{array}{l}\text { Sensasi Penjalaran } \\
\text { - Ya } \\
\text { - Tidak }\end{array}$ & $\begin{array}{c}17(94,4) \\
1(5,6)\end{array}$ & $\begin{array}{l}21(53,8) \\
18(46,2)\end{array}$ & $0,003 *$ \\
\hline $\begin{array}{l}\text { Pola Nyeri } \\
\text { - Nyeri menetap, terus-menerus, sedikit fluktuasi } \\
\text { - Nyeri menetap disertai serangan nyeri yang lebih kuat } \\
\text { - Nyeri hilang dan timbul tanpa rasa sakit diantaranya } \\
\text { - Serangan-serangan nyeri diantara rasa nyeri yang ada }\end{array}$ & $\begin{array}{c}0(0) \\
1(5,6) \\
1(5,6) \\
16(88,8)\end{array}$ & $\begin{array}{c}2(5,1) \\
3(7,6) \\
9(23,1) \\
25(64,1)\end{array}$ & $0,240 *$ \\
\hline $\begin{array}{l}\text { Terbakar } \\
\text { - Ya } \\
\text { - Tidak }\end{array}$ & $\begin{array}{c}15(83,3) \\
3(16,7)\end{array}$ & $\begin{array}{c}4(10,3) \\
35(89,7)\end{array}$ & $<0,001 *$ \\
\hline $\begin{array}{l}\text { Kesemutan } \\
\text { - Ya } \\
\text { - Tidak }\end{array}$ & $\begin{array}{c}15(83,3) \\
3(16,7)\end{array}$ & $\begin{array}{c}7(17,9) \\
32(82,1)\end{array}$ & $<0,001 *$ \\
\hline $\begin{array}{l}\text { Alodinia } \\
\text { - Ya } \\
\text { - Tidak }\end{array}$ & $\begin{array}{c}5(27,8) \\
13(72,2)\end{array}$ & $\begin{array}{c}1(2,6) \\
38(97,4)\end{array}$ & $0,010 * *$ \\
\hline $\begin{array}{l}\text { Tersetrum } \\
\text { - Ya } \\
\text { - Tidak }\end{array}$ & $\begin{array}{c}11(61,1) \\
7(38,9)\end{array}$ & $\begin{array}{c}1(2,6) \\
38(97,4)\end{array}$ & $<0,001 * *$ \\
\hline $\begin{array}{l}\text { Sensitif Perubahan Suhu } \\
\text { - Ya } \\
\text { - Tidak }\end{array}$ & $\begin{array}{c}7(38,9) \\
11(61,1)\end{array}$ & $\begin{array}{c}0(0) \\
39(100)\end{array}$ & $<0,001 * *$ \\
\hline $\begin{array}{l}\text { Baal } \\
\text { - Ya } \\
\text { - Tidak }\end{array}$ & $\begin{array}{c}18(100) \\
0(0)\end{array}$ & $\begin{array}{l}13(33,3) \\
26(66,7)\end{array}$ & $<0,001 *$ \\
\hline $\begin{array}{l}\text { Nyeri Tekan } \\
\text { - Ya } \\
\text { - Tidak }\end{array}$ & $\begin{array}{c}7(38,9) \\
11(61,1)\end{array}$ & $\begin{array}{c}3(7,7) \\
36(92,3)\end{array}$ & $0,008 * *$ \\
\hline
\end{tabular}

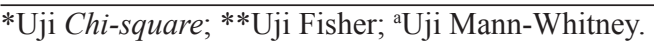

merupakan jenis kanker terbanyak secara umum. Adapun Reis-Pina dkk mendapatkan rasio laki-laki dan perempuan hampir 1:1, yaitu 53,3\% perempuan. $^{9}$

Usia rerata subjek dalam penelitian ini adalah $45,91 \pm 12,41$ tahun, jauh lebih muda dibandingkan dengan penelitian Reis-Pina dkk (62,1 tahun) dan Couceiro dkk (55,3 tahun). ${ }^{8-9}$ Namun, telaah sistematis oleh Roberto dkk menyatakan median umur pada pasien dengan nyeri kanker neuropatik adalah 48 tahun. ${ }^{3}$ Perbedaan rerata umur pada subjek mungkin diakibatkan oleh perbedaan epidemiologi dan faktor risiko yang menyebabkan lebih mudanya demografi penderita kanker di Indonesia. Penelitian oleh Anwar dkk menyatakan bahwa rerata umur penderita kanker payudara di Indonesia adalah 48 tahun dan di dunia adalah 68 tahun. ${ }^{10}$ Selain itu, Wong dkk menyebutkan bahwa ras Asia dan penduduk negara berkembang memiliki kecenderungan untuk menderita kanker payudara pada umur yang lebih muda. ${ }^{11}$ Belum ada penjelasan secara biologis yang kuat mengapa terdapat kecenderungan ini. Namun, secara epidemiologis Mousavi-Jarrahi menyatakan 
Tabel 3. Hubungan Karakteristik Subjek dengan Nyeri Neuropatik $(\mathbf{n}=57)$

\begin{tabular}{|c|c|c|c|}
\hline \multirow[b]{2}{*}{ Variabel } & \multicolumn{2}{|c|}{ Nyeri Neuropatik } & \multirow[b]{2}{*}{$\mathbf{p}$} \\
\hline & $\begin{array}{c}\text { Ya } \\
(n=18) \\
n(\%)\end{array}$ & $\begin{array}{c}\text { Tidak } \\
(\mathbf{n}=39) \\
\text { n(\%) }\end{array}$ & \\
\hline $\begin{array}{l}\text { Usia(tahun), } \\
\text { Rerata+SD }\end{array}$ & $47,06 \pm 11,81$ & $45,38 \pm 12,788$ & $0,641^{\mathrm{a}}$ \\
\hline $\begin{array}{l}\text { Jenis Kelamin } \\
\text { - Laki-laki } \\
\text { - Perempuan }\end{array}$ & $\begin{array}{c}7(38,9) \\
11(61,1)\end{array}$ & $\begin{array}{l}13(33,3) \\
26(66,7)\end{array}$ & $0,683 *$ \\
\hline $\begin{array}{l}\text { Jenis Tumor } \\
\text { - Mammae } \\
\text { - Limfoma } \\
\text { - Kepala/leher } \\
\text { - Paru } \\
\text { - Urogenital }\end{array}$ & $\begin{array}{c}8(36,4) \\
2(28,6) \\
5(45,5) \\
2(40) \\
1(8,3)\end{array}$ & $\begin{array}{c}14(63,6) \\
5(71,4) \\
6(54,5) \\
3(60) \\
11(91,7)\end{array}$ & $0,354 *$ \\
\hline $\begin{array}{l}\text { Lokasi Nyeri } \\
\text { - Tumor lokal } \\
\text { - Metastasis }\end{array}$ & $\begin{array}{c}0(0) \\
18(100)\end{array}$ & $\begin{array}{l}12(30,8) \\
27(69,2)\end{array}$ & $0,011 * *$ \\
\hline
\end{tabular}

bahwa mudanya usia kanker payudara pada populasi Asia disebabkan oleh penelitian-penelitian dengan proporsi orang muda lebih banyak pada populasi Asia, sehingga menurunkan rerata umur subjek penelitian. ${ }^{12}$

Dalam penelitian ini, tidak terdapat perbedaan umur antara pasien nyeri kanker neuropatik dengan pasien nyeri kanker non-neuropatik, sejalan dengan penelitian Couceiro dkk. ${ }^{8}$ Namun, hal ini berbeda dengan Reis-Pina dkk dan Roberto dkk yang menyatakan terdapat perbedaan umur dan adanya kecenderungan pasien yang menderita nyeri kanker neuropatik berusia lebih muda dibandingkan nonneuropatik. ${ }^{3,9}$ Salah satu efek samping kemoterapi pada pasien kanker adalah kerusakan saraf perifer. Pada pasien geriatri, kemoterapi tidak dilakukan secara agresif karena menurunnya preservasi fungsi fisiologis pada tubuh, sehingga efek samping nyeri neuropatik akibat kemoterapi lebih sedikit terjadi.

Jenis kanker dalam penelitian ini sebagian besar adalah kanker payudara (36,8\%), hampir sama dengan Couceiro dkk, yaitu 40,8\% subjek menderita kanker payudara. ${ }^{8}$ Namun, hal ini berbeda dengan Reis-Pina dkk yang mendapati hanya $11,6 \%$ subjek dengan kanker payudara. ${ }^{9}$ Proses rekrutmen subjek dalam penelitian Couceiro dkk memiliki kesamaan dengan studi ini, sedangkan Reis-Pina dkk berbeda proses dengan studi ini, yaitu perekrutan subjek penelitian dengan proses konsultasi dari dokter utama ke klinik nyeri.

Dalam penelitian ini, jenis kanker tidak memiliki hubungan dengan adanya nyeri neuropatik. Hal ini senada dengan Couceiro dkk bahwa tidak ada kecenderungan nyeri neuropatik pada jenis kanker tertentu. ${ }^{8}$ Meskipun efek massa tumor dapat menyebabkan nyeri neuropatik, efek samping terapi yang didapatkan pada kanker memiliki pengaruh besar dalam kejadian nyeri kanker neuropatik.

Sebanyak $78,9 \%$ subjek yang mengalami nyeri kanker dalam penelitian ini merupakan tumor metastasis spinal, yang menyebabkan pasien dikonsulkan ke bagian neurologi, bahkan seluruh subjek dengan nyeri neuropatik adalah akibat lesi metastasis. Lesi metastasis di jaringan muskuloskeletal akan mengganggu stabilitas mekanik. Proses ini juga disertai edema jaringan sekitar dan aktifasi proses resorpsi tulang secara berkelanjutan. Kesemua proses ini akan mengaktifkan serabut saraf bebas dan menimbulkan nyeri terutama saat mobilisasi. Hal ini sesuai bahwa sebanyak $64 \%$ pasien kanker tahap lanjut akan mengalami nyeri kanker. ${ }^{9}$ Prevalensi nyeri kanker neuropatik dalam penelitian ini adalah $31,6 \%$, hampir sama dengan telaah sistematis yang dibuat oleh Roberto dkk (31,2\%) serta Reis-Pina dkk $(32,4 \%) .{ }^{3,9}$

Tidak terdapat perbedaan pola nyeri antara subjek dengan dan tanpa nyeri neuropatik, bahwa kedua kelompok mengalami nyeri yang hilang timbul tanpa rasa nyeri di antaranya. Hal ini sesuai dengan karakteristik pada nyeri kanker, yaitu nyeri yang bersifat kronik dengan adanya campuran komponen nyeri nosiseptif dan nyeri neuropatik. Proses nyeri neuropatik yang terjadi melibatkan mekanisme perifer dan mekanisme sentral.

Subjek dengan nyeri neuropatik dalam penelitian ini mengalami nyeri seperti penjalaran, sensasi terbakar, tersetrum, alodinia, sensitif terhadap perubahan suhu, baal, nyeri terhadap penekanan, sesuai dengan karakteristik yang khas untuk nyeri 
neuropatik. Proses nyeri neuropatik kanker terjadi akibat dari beberapa proses patologis di sistim somatosensori dengan mekanisme perifer dan sentral. Dalam mekanisme perifer, sel tumor akan mensekresi berbagai faktor yang diperlukan untuk pertumbuhannya, seperti bradikinin, kanabinoid, endotelin, interleukin dsb yang merangsang reseptor bebas nyeri. Sel tumor itu sendiri dapat menginfiltrasi jaringan ikat disekitarnya yang mengandung serabut saraf bebas atau menginfiltrasi jaringan saraf mengakibatkan diskontinuitas dan fragmentasi dari sel saraf. Formasi neuroma terinduksi sel tumor menyebabkan ketidakseimbangan saluran ion natrium sehingga menyebabkan eksitasi spontan dan cetusan ektopik. Dalam mekanisme sentral, terjadi reorganisasi struktur yang signifikan sehingga terjadi perubahan komunikasi dari struktur saraf, seperti hilangnya modulasi inhibisi sinyal nyeri. ${ }^{1-2,4,13}$

Dalam penelitian ini, penanganan nyeri kanker dilakukan sesuai dengan panduan World Health Organisation (WHO) Cancer Pain Ladder for Adults, sehingga didapatkan penurunan nilai NRS $>50 \%$ pada $65 \%$ pasien berdasarkan panduan tersebut. Sebanyak $80,7 \%$ subjek mendapat opioid dan $36,8 \%$ mendapat golongan antikonvulsan. Hal ini sesuai dengan telaah sistematis oleh Carlson bahwa terdapat pengurangan NRS dan VAS sebesar 20-81\% pada pasien yang ditatalaksana dengan panduan tersebut, bahkan $50-90 \%$ pasien mengalami penurunan tingkat nyeri menjadi "tidak ada" atau "ringan". Hasil dalam penelitian ini menunjukkan bahwa implementasi panduan ini sudah berjalan dengan baik dengan berkurangnya nyeri $>50 \%$ pada $64,9 \%$ subjek. $^{14}$

Terdapat beberapa keterbatasan dalam penelitian ini. Jumlah subjek yang diambil belum memenuhi sampel minimal sehingga tingkat kepercayaan penelitian masih belum sesuai harapan. Pasien yang dijadikan subjek hanya pasien yang dikonsultasikan ke bagian neurologi, sehingga pasien yang tidak dikonsultasikan dari departemen lain tidak dilakukan penapisan. Juga belum dinilai derajat fungsional, kualitas hidup, defisit neurologis, gambaran radiologis, pengkajian neuropsikiatri serta profil terapi, dan faktor-faktor lain yang berpengaruh pada nyeri kanker neuropatik yang dapat dilakukan penelitian selanjutnya. Selain akibat kanker dan/ atau terapinya, nyeri neuropatik dapat disebabkan oleh neuropati diabetik, defisiensi vitamin B12, dan komorbiditas lainnya. Hal ini belum terkaji dalam penelitian kami sehingga masih dapat terjadi kerancuan. Namun, penelitian ini dapat memberikan gambaran nyeri kanker neuropatik pada pasien kanker di Indonesia. Dalam penelitian ini, riwayat terapi pada kanker tidak dikaji secara mendalam. Regimen radioterapi dan kemoterapi serta dosis, lokasi, dan frekuensi tidak diikutsertakan sehingga belum dapat diinvestigasi pengaruh dari pengobatan tersebut terhadap nyeri kanker.

Penelitian ini merupakan penelitian pertama yang dilakukan mengenai nyeri kanker neuropatik di Indonesia dengan menggunakan kuesioner PainDETECT dalam mendiagnosis nyeri neuropatik pada pasien kanker. Namun, investigasi nyeri neuropatik menggunakan metode lain sangat dianjurkan mengingat sensitivitas yang rendah sehingga tidak dapat menyingkirkan pasien tanpa nyeri neuropatik meskipun skor PainDETECT $<19$.

\section{KESIMPULAN}

Didapatkan prevalensi nyeri neuropatik pada pasien dengan nyeri kanker sebesar 31,6\% yang kesemuanya ditemukan pada tumor metastasis. Pada pasien dengan nyeri kanker neuropatik merasa nyeri yang berat dan menjalar. Seluruh pasien ditemukan defisit sensorik rasa baal dan proporsi 83,3\% pasien merasa terbakar dan kesemutan pada daerah kanker. Selain itu, seluruh pasien dengan nyeri kanker neuropatik merasakan nyeri pada lokasi metastasis.

\section{DAFTAR PUSTAKA}

1. Budisulistyo T, Sofyan HR. Nyeri kanker. Dalam: Aninditha T, Andriani R, Malueka RG, editors. Buku Ajar Neuroonkologi. Jakarta: Penerbit Kedokteran Indonesia; 2019. h. 314-37.

2. Esin E, Yalcin S. Neuropathic cancer pain: what we are dealing with? How to manage it? Onco Targets Ther. 2014;7:599-618.

3. Roberto A, Deandrea S, Greco MT, Corli O, Negri E, Pizzuto M, dkk. Prevalence of neuropathic pain in cancer patients: pooled estimates from a systematic review of published literature and results from a survey conducted in 50 italian palliative care centers. J Pain Symptom Manage. 2016;51(6):1091-2e4. 
4. Yoon SY, Oh J. Neuropathic cancer pain: prevalence, pathophysiology, and management. Korean J Intern Med. 2018;33(6):1058-69.

5. Margareta K, Aninditha T, Hakim M, Herqutanto, Kurniawan M. Adaptasi transkultural kuesioner painDETECT ke dalam Bahasa Indonesia. Neurona. 2017;34(3).

6. Tzamakou E, Petrou A, Tefa L, Siafaka V, Laou E, Tzimas P, dkk. Detection of neuropathic pain in endstage cancer patients: diagnostic accuracy of two questionnaires. Pain Pract. 2018;18(6):768-76.

7. Caraceni A, Shkodra M. Cancer pain assessment and classification. Cancers (Basel). 2019;11(4).

8. Couceiro TCM, Lima LC, Junior MPC, Mello PFLSO, Ferreira TMML, Firmino ALP. Prevalence of neuropathic pain in patients with cancer. Br J Pain. 2018;1(3):231-5.

9. Reis-Pina P, Acharya A, Lawlor PG. Cancer pain with a neuropathic component: a cross-sectional study of its clinical characteristics, associated psychological distress, treatments, and predictors at referral to a cancer pain clinic. J Pain Symptom Manage. 2018;55(2):297-306.
10. Anwar SL, Raharjo CA, Herviastuti R, Dwianingsih EK, Setyoheriyanto D, Avanti WS, dkk. Pathological profiles and clinical management challenges of breast cancer emerging in young women in Indonesia: a hospital-based study. BMC Womens Health. 2019;19(1):28.

11. Wong FY, Tham WY, Nei WL, Lim C, Miao H. Age exerts a continuous effect in the outcomes of Asian breast cancer patients treated with breast-conserving therapy. Cancer Commun (Lond). 2018;38(1):39.

12. Mousavi-Jarrrahi SH, Kasaeian A, Mansori K, Ranjbaran M, Khodadost M, Mosavi-Jarrahi A. Addressing the younger age at onset in breast cancer patients in Asia: an age-period-cohort analysis of fifty years of quality data from the international agency for research on cancer. ISRN Oncol. 2013;2013:429862.

13. Edwards HL, Mulvey MR, Bennett MI. Cancerrelated neuropathic pain. Cancers. 2019;11:373.

14. Carlson CL. Effectiveness of the World Health Organization cancer pain relief guidelines: an integrative review. J Pain Res. 2016;9:515-34. 